\title{
EN EL FILO DE LA DUDA: INVESTIGACIÓN EPIDEMIOLÓGICA Y ASPECTOS BIOÉTICOS Y PSICOLÓGICOS EN LA PANDEMIA DE VIH
}

\section{And the Band Played On: Epidemiological Research and Bioethical and Psychological Aspects in the HIV Pandemic}

\author{
Irene CAMBRA-BADII ${ }^{a, b}$; Magí FARRÉc,d; Jorge PÉREZ \\ ${ }^{a}$ Càtedra de Bioètica. Universitat de Vic - Universitat Central de Catalunya. Vic (España). ${ }^{\text {b} G r u p o ~ d e ~}$ \\ Investigación Educativa en Ciencias de la Salud (GRECS). Universidad Pompeu Fabra (UPF). Barcelona (España). \\ ${ }^{\mathrm{C}}$ Facultad de Medicina. Universitat Autònoma de Barcelona. Barcelona (España). ${ }^{d}$ Servicio de Farmacología \\ Clínica. Hospital Universitario Germans Trias i Pujol-IGTP. Badalona (España).
}

Correo electrónico: jordi.perez@upf.edu

Fecha de recepción: 14 de septiembre de 2020

Fecha de aceptación: 18 de septiembre de 2020

Fecha de publicación: 29 de enero de 2021

\section{Resumen}

La pandemia de VIH (virus de inmunodeficiencia humana) y el espectro de enfermedades de su síndrome (SIDA) se registran por primera vez a principios de los años 1980 en Estados Unidos, con casos de muerte por neumonías asociados con el sarcoma de Kaposi. La investigación epidemiológica llevada a cabo por distintos equipos en los Estados Unidos -haciendo foco principalmente en el Centro para el Control y Prevención de Enfermedades- aparece retratada en la película En el filo de la duda / And the band played on (1993), de Roger Spottiswoode. Casi 30 años luego de su estreno, la película es sumamente actual y retrata de manera muy ajustada los hechos sucedidos en la investigación. En este artículo se presenta un análisis detallado del proceso investigativo, las cuestiones bioéticas implicadas y los factores psicológicos que permiten analizar los enfrentamientos grupales y sociales del acontecimiento epidemiológico que marcó un antes y un después en el siglo XX. Se sugiere utilizar la película como herramienta docente.

Palabras clave: pandemia; $\mathrm{VIH}$; investigación; investigación epidemiológica; bioética; psicología. 


\begin{abstract}
The HIV pandemic and the spectrum of diseases associated with its syndrome (AIDS) were noted for the first time in the early 1980s in the United States, with cases of death from pneumonia associated with Kaposi's sarcoma. The epidemiological investigation carried out by different teams in the United States -but mainly focusing on the Centers for Disease Control and Prevention- is portrayed in the film And the band played on (1993), by Roger Spottiswoode. Almost 30 years after its release, the film is still iconic and closely portrays the events of the investigation. This article presents a detailed analysis of the research process, the bioethical issues involved, and the psychological factors that allows to analyze the group and social confrontations of the epidemiological event that marked a before and after in the 20th century. It is suggested to use the film as a teaching tool.
\end{abstract}

Keywords: pandemic; HIV; research; epidemiological research; bioethics; psychology.

FICHA TÉCNICA

Título: En el filo de la duda (España) / Y la banda siguió tocando (Latinoamérica).

Título original: And the band played on (película de TV por cable, HBO).

Año: 1993.

Duración: 140 minutos.

País: Estados Unidos.

Dirección: Roger Spottiswoode.

Guion: Arnold Schulman (Novela: Randy Shilts).

Música: Carter Burwell.

Fotografía: Paul Elliott.

Montaje: Lois Freeman-Fox.

Reparto: Matthew Modine, Alan Alda, Richard Gere, Phil Collins, Patrick Bauchau, David Dukes, Anjelica Huston, Steve Martin, Swoosie Kurtz, Richard Jenkins, Glenne Headly, Ian McKellen, Lily Tomlin, Nathalie Baye, Charles Martin Smith, Laura Innes, BD Wong.

Productora: HBO, Odissey Entertainment, SpeIling Entertainment.

Género: drama; enfermedad; sida; telefilm.

Sinopsis: Minucioso relato de las reacciones sociales ante el descubrimiento del SIDA y el tenso trabajo de los profesionales y médicos que lo investigan (Filmaffinity).

Premios: 14 nominaciones y 3 premios Emmy (1994) incluyendo mejor telefilm y casting. Globos de oro 1993: nominada Mejor

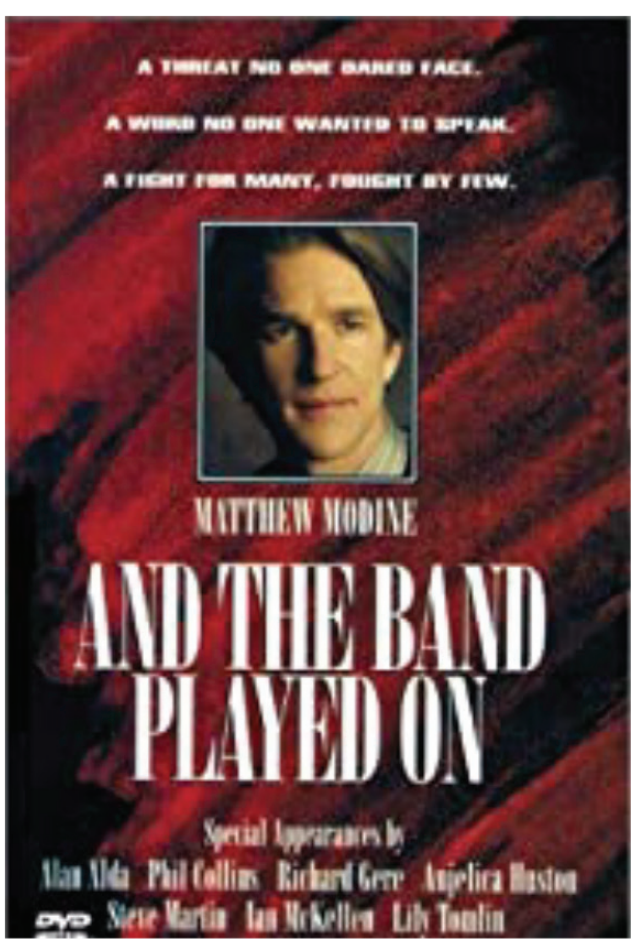

miniserie o película para TV y actor (Modine). Sindicato de Directores (1993): Nominada a Mejor director (Miniserie/Telefilm). Festival de Montreal (1993): Gran Premio Especial del Jurado. 


\section{Enlaces:}

https://www.imdb.com/title/tt0106273 /?ref_=fn_al_tt_1

https://www.filmaffinity.com/es/film2012 78.html

\section{INTRODUCCIÓN}

La película Y la banda siguió tocando / En el filo de la duda / And the band played on (1993), de Roger Spottiswoode, es una de las mejores películas donde se representa un proceso de investigación epidemiológica a partir del surgimiento de una nueva enfermedad. Basada en el libro original de Randy Shilts de $1987^{1}$, sigue las historias reales de la investigación del descubrimiento del virus de inmunodeficiencia humana (de aquí en adelante, VIH) a comienzos de los años 1980. Ha sido calificada como un docu-drama por su tratamiento pormenorizado del problema de investigación, como si fuese un documental ${ }^{2}$, y ha sido utilizada en múltiples ocasiones para la docencia de las ciencias de la salud ${ }^{3-8}$. En la Revista de Medicina y Cine (RMC) ha aparecido en dos artículos, uno sobre películas referentes a la enfermedad ${ }^{4}$ y otro donde había sido usada para mejorar la enseñanza de la microbiología ${ }^{6}$. Sin embargo, no se han realizado publicaciones específicas que analicen su argumento y su articulación con las ciencias de la salud, razón por la cual describiremos en detalle el proceso histórico que se retrata en el film.

A continuación se expone de forma exhaustiva la sinopsis de la película ligada al proceso de investigación sobre la enfermedad, que el lector informado sobre la misma puede obviar, y se destacan aspectos psicológicos y bioéticos susceptibles de reflexión al utilizar la película con fines docentes.

\section{EL PROCESO DE INVESTIGACIÓN COMO UN PROCESO HISTÓRICO}

La película narra los hechos sucedidos entre 1977 y 1985 relacionados con el descubrimiento mundial del virus del VIH. El prólogo se ambienta en Zaire en 1976, en un pequeño poblado a orillas del río Ébola, donde el epidemiólogo estadounidense Don Francis llega como parte de una delegación de dos médicos de la Organización Mundial de la Salud para asistir en un brote epidémico de una nueva enfermedad. Casi todos los nativos han muerto debido a este extraño brote. En la película no se aclara, pero sabemos que se mismo año se identifica la fiebre hemorrágica del Ébola, una de las enfermedades infecciosas más letales, que ha tenido diversos brotes epidémicos hasta 2015. La película anuncia: "La epidemia de Ébola fue contenida antes de que alcanzara a todo el mundo. No era VIH, pero sí una advertencia de lo que estaba por venir".

La acción se traslada entonces a los primeros casos de aparición de la enfermedad: en 1977, una mujer joven en el Hospital Nacional de Dinamarca, en Copenhague, muerta por neumonía por neumocistosis sin enfermedades previas, y en 1978, en el Hospital Claude Bernard de Paris, otro caso extraño de un paciente adulto con neumocistosis pero que luego contrae hongos en la boca, verrugas en los brazos y en las piernas.

La película comienza su narración central dos años más tarde, en 1980, con el panorama político de los Estados Unidos. Por un lado, con la reivindicación de uno de los representantes de la comunidad gay, Bill Kraus, durante una convención demócrata, y por otro lado, con el triunfo de Ronald Reagan como candidato republicano en las elecciones de ese año. Este panorama nos pone sobre aviso: la comunidad gay no es aceptada por ninguno de los dos partidos políticos más importantes de los Estados Unidos. Mientras Reagan aparece por televisión, en el Centro Médico UCLA de Los Ángeles los médicos debaten un caso extraño de un paciente sin Linfocitos T: "su sistema inmunológico desapareció".

La acción continúa en 1981 en el Centro para el Control y Prevención de Enfermedades (de aquí en adelante, CDC según sus siglas en inglés) del Gobierno de Estados Unidos, en 
Atlanta. Una de las médicas e investigadoras del equipo, Mary Guinan, solicita al jefe de departamento que dé atención inmediata a un informe: "Parece que hay una rara epidemia entre los gays de Los Ángeles. Ha habido cinco casos de neumocistosis sin una enfermedad previa dentro de los últimos meses... y ya hay dos decesos. Además, he llamado a Nueva York y a San Francisco y han tenido casos similares. Esto debe entrar en el boletín semanal de noticias a la brevedad". El jefe tacha la palabra "gay" del título del informe y explicita que lo hace para que sea difundido por el gobierno de Reagan.

A partir de ese momento, la película incluye como bitácora no sólo el panorama político sino también la cantidad de contagios y de decesos de esta extraña enfermedad. Don Francis, aquel médico que había ido a Zaire, forma parte ahora del CDC porque en los últimos tres años estuvo investigando sobre hepatitis $B$ en hombres homosexuales. Comienzan entonces las reuniones grupales para organizar la investigación epidemiológica, en un principio centrada en la comunidad gay.

El jefe, James Curran, comienza la reunión diciendo: "Tenemos que hacer llamadas y contactar a las oficinas de salud en las principales áreas urbanas de manera que puedan hacer una investigación interna hospitalaria. Tenemos que hablar con los pacientes, sus doctores, amigos y parientes". Pese a no tener permitido hacer preguntas personales, en la lluvia de ideas grupal surgen preguntas sobre el estilo de vida, relaciones sexuales, productos de limpieza, mascotas, dieta alimenticia, consumo de drogas... para buscar la coincidencia de causas que pudieran explicar la enfermedad. Todos los investigadores del equipo van al terreno para realizar estas entrevistas.

Julio 1981. 80 casos en Estados Unidos - 26 muertes. Uno de los investigadores del equipo se reúne con el representante de la comunidad gay que había aparecido al inicio de la película. Bill
Kraus actúa como informante clave y le cuenta que, si bien muchos tienen pareja estable, hay varios miles que asisten a las saunas de la ciudad para tener sexo. Con la ayuda de Selma Dritz, del Departamento de Salud de la ciudad de San Francisco, hacen una inspección a uno de las saunas donde el investigador se sorprende por las conductas de quienes asisten: más de mil personas por día tienen encuentros sexuales allí, algunos siendo completamente desconocidos y anónimos, o utilizando drogas. Estas sustancias, incluido el nitrito de amilo, se llevan al laboratorio para analizarlas, pero no arrojan resultados concluyentes que puedan unirlas con la extraña enfermedad.

Septiembre 1981. Una nueva reunión del equipo del CDC comienza con la muletilla del jefe de la investigación, que se repite en varias reuniones y momentos de la película: ¿Qué pensamos? ¿Qué sabemos? ¿Qué podemos probar? El grupo aporta los resultados que tienen hasta ahora y se va produciendo el intercambio con una lógica investigativa: "¿Sólo gays?", "Pienso eso, pero no lo puedo probar"; "¿Sólo hombres?", "Pienso eso, pero no lo puedo probar"; "¿Depositadores de semen?" "Si está en el semen, a no ser que haya algo inusual en esa enfermedad, no debería hacer diferencia si es depositado en el ano o en la vagina, lo que significa que las mujeres podrían tenerlo también". Lo único que saben es que el sistema inmune deja de funcionar por completo: "¿en todos los casos?" "Eso lo sabemos, pero no lo podemos comprobar". Y concluyen: "es un agente infeccioso con una alta probabilidad de transmisión sexual". "¿Una bacteria o un virus?". "Pienso que un virus". Otro investigador lanza una nueva pregunta que hace lugar a lo inédito: "Asumamos que es un virus. ¿Es un virus que ya conocemos y se ha vuelto fatal, o es uno nuevo que no habíamos visto nunca?". Las estadísticas son apabullantes: "En siete meses, el número de casos pasó de 5 a 152 en 15 estados. Pero lo más siniestro es que hasta ahora la tasa de mortalidad 
es del $40 \%$. Y los doctores que tratan pacientes gay dicen que la mortalidad puede llegar a ser de un $100 \% "$. A partir de este intercambio se formaliza la investigación basada en la hipótesis de la transmisión sexual, por un plazo de tres meses -asumiendo que les alcanzará el plazo de cualquier otra enfermedad. Por supuesto, sabemos que esto no será posible porque esta enfermedad no es como las anteriores.

Noviembre 1981. 160 casos en Estados Unidos - 88 muertes. Mary entrevista a un hombre asintomático, quien reflexiona frente al desfile de la comunidad gay: "La fiesta terminó".

295 casos en Estados Unidos - 119 muertes. En la pizarra de Francis aparece la expresión "Butcher Bill" y debajo el número de casos y fallecidos. Así se refieren en el ejército a las bajas mortales en la batalla, y así anotaba su mentor en una antigua investigación. Francis comenta los resultados de la investigación de control de casos del análisis sanitario: "Inyectamos las muestras en ratas, conejos, cobayos y trataremos con monos. Hasta ahora, no hallamos rastros de parásitos, hongos o virus (...) Todo lo que sabemos es que la enfermedad es causada por organismos que no podemos ver o encontrar. No sabemos si es un agente infeccioso o una combinación. No sabemos cómo se transmite." La solicitud de un microscopio electrónico encuentra su respuesta en el discurso de Reagan que se transmite por televisión: van a duplicar el gasto de Defensa y no van a privilegiar la investigación científica $-\mathrm{y}$ menos aún, una investigación que tome como grupo central a la comunidad gay. Francis es interrumpido por la noticia de que hay un brote de una enfermedad similar en la población haitiana de Miami, y que ninguno es gay. En San Francisco, once bebés recién nacidos tienen la enfermedad. "Ya no se trata de una enfermedad gay" sentencia el jefe del equipo. Sin embargo, en la escena siguiente, se ve cómo la enfermedad aparece por primera vez en la prensa televisiva señalando que los dos pacientes eran hombres homosexuales.
La frustración de Francis por no saber por dónde continuar con la investigación encuentra un alivio en un insight que tiene cuando su compañero se divierte con el videojuego Pac-Man: "algo se está devorando las células T" como el pac-man o come-cocos devora los "premios" en la pantalla. La hipótesis sigue entonces por el camino de una enfermedad infecciosa, que Francis piensa como una combinación del virus de la leucemia felina (ambos causan cáncer, inmunosupresión y tienen largos períodos de incubación) y la hepatitis $B$ (que también causa cáncer, tiene largos períodos de incubación y se transmite sexualmente). Sin embargo, un colega señala que puede estar "viendo" estas dos enfermedades porque coinciden con sus áreas de experticia. El hecho de aplicar los conocimientos previos para explicar lo inédito puede funcionar como avance y también como obstáculo, intentando que un nuevo acontecimiento quepa en las clasificaciones anteriores, a la manera del lecho de Procusto.

Más tarde se confirma que buscan un nuevo virus y la película presenta al científico Robert (Bob) Gallo: "un hombre que se hizo mundialmente famoso por hallar el primer retrovirus humano, HTLV. Aún no encontró la principal enfermedad con la que se relaciona. Y si esto sale bien... conseguirá el Premio Nobel".

Mientras tanto, el equipo sigue entrevistando pacientes buscando conexiones entre ellos a partir de que hayan mantenido relaciones sexuales. Muchos han muerto ya. Los caminos de la investigación conducen al primer paciente que Mary había entrevistado en Nueva York, un azafato de vuelo que se muestra reticente en un primer lugar, porque no sabía que la enfermedad se transmitía sexualmente y pensaba que tenía un cáncer de piel, pero luego comparte la información de 73 personas con quien mantuvo relaciones sexuales y que pueden ser localizadas. Esto permite hacer un estudio de conglomerados de las personas infectadas considerando al azafato como paciente cero y "sugiriendo 


\section{EN EL FILO DE LA DUDA: INVESTIGACIÓN EPIDEMIOLÓGICA Y ASPECTOS \\ BIOÉTICOS Y PSICOLÓGICOS EN LA PANDEMIA DE VIH \\ IRENE CAMBRA-BADII; MAGÍ FARRÉ; JORGE PÉREZ}

fuertemente" que la enfermedad se transmite sexualmente al tener 40 casos en 10 ciudades que se conectan con ese paciente cero. El equipo felicita al investigador: "es la primera señal de una prueba real".

Luego de esta certeza, vienen nuevas preguntas: "¿Hay alguna señal de por qué el paciente cero sigue vivo y otros de este grupo murieron casi inmediatamente?", "Asumimos que hay un período de incubación"; "¿Cuántas de estas conexiones se dieron en un sauna?", "La gran mayoría". Considerando que las saunas pueden ser los lugares donde se multiplican las situaciones de propagación de los contagios, Francis aporta la idea de cerrarlas, pero el jefe se niega: señala que el gobierno federal no tiene autoridad para cerrarlas y que tomar esas medidas no forma parte de su rol como científicos (Foto 1).

Junio 1982. Por primera vez, el jefe del equipo informa a la sociedad sobre la existencia de esta nueva enfermedad en una conferencia de prensa. Sin embargo, el mensaje sobre su transmisión es ambiguo: "La existencia de un estudio de grupo ofrece evidencias de una hipótesis que la gente en el estudio no están asociadas al azar. Este estudio es de un grupo sexual, pero aún no tenemos evidencia científica para decir con certeza cómo una persona lo transmite a otra persona. Tenemos que hacer estudios en el área para no dar información que no esté validada".

Esto acrecienta las diferencias entre el jefe y Francis, que discuten sobre qué información es

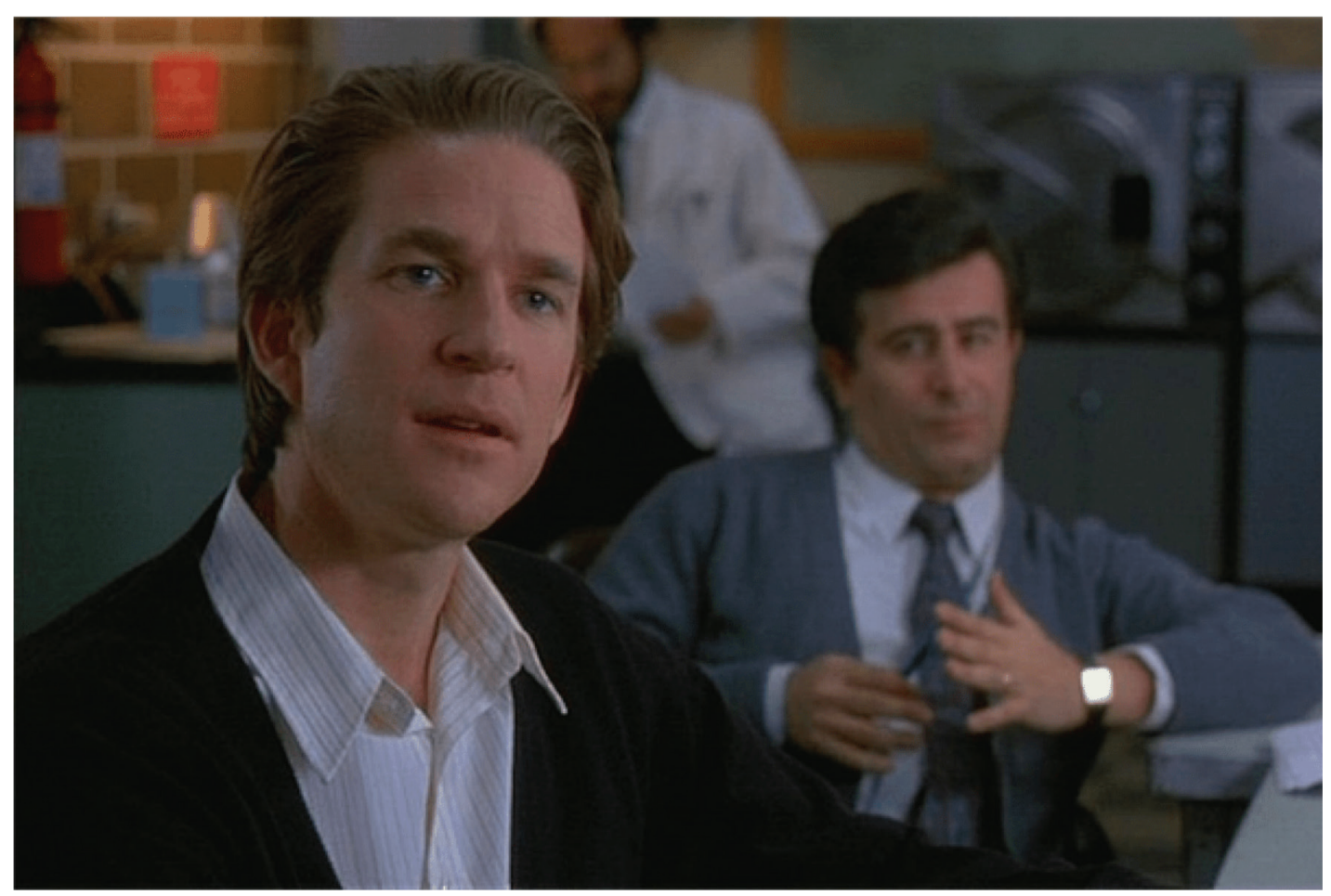

Foto 1. Discusiones en el equipo de investigación. En primer plano, el Dr. Francis; y más atrás Curran, el jefe. 
necesario compartir con la sociedad: ¿̇es mejor no generar pánico, o impedir que siga creciendo la epidemia? ¿Es posible avanzar en la investigación sin presionar al gobierno, en definitiva, quienes financian el proyecto? La premura del tiempo de los contagios y la elevada cantidad de muertos pone al jefe en un callejón sin salida: ¿cuánta gente se va a enfermar hasta tener una prueba establecida científicamente?

405 casos en Estados Unidos - 272 muertes. Mientras en la comunidad gay de San Francisco se debate el cierre de las saunas, en Nueva York uno de los entrevistados da a Mary una donación para la investigación. Se produce luego una fuerte discusión en la reunión organizada por el Departamento de Salud en San Francisco. Como la conferencia de prensa previa fue dudosa respecto a la hipótesis de la transmisión sexual, la comunidad gay acude organizada tratando de impedir el cierre de las saunas. Francis anuncia que habla a título personal y no del CDC, y dice: "puede haber confusión por la forma en que la información se ha dado... sobre si esta enfermedad se transmite sexualmente o no. Estoy aquí para informarles lo que hemos encontrado. Primero, si contraen esta enfermedad, la posibilidad de morir es del $100 \%$. Segundo, una de las maneras de contraerla es teniendo sexo con alguien que ya la ha contraído. Hemos comprobado que la mayoría de las personas afectadas tuvieron sexo en saunas". Esto provoca la ira entre los asistentes: "Es otro truco de Reagan para que nos volvamos a meter en el armario", "es nuestro asunto decidir cómo y dónde elegimos tener sexo", "prefiero morir como ser humano a seguir viviendo como un monstruo" (Foto 2). El director del Departamento de Salud propone una votación entre los asistentes antes de tomar su decisión de cierre, que resulta en una abrumadora mayoría en contra de cerrar las saunas.

Mientras tanto, se articula la investigación epidemiológica con el laboratorio: la película muestra cómo trabaja el grupo de Luc Montagnier en el Instituto Pasteur de Paris en Francia y el equipo de Robert de Gallo en los Estados Unidos, pero no llegan aun a resultados concluyentes, aunque los franceses avanzan más rápidamente.

En Atlanta, uno de los investigadores del CDC llega con la noticia de que una mujer consumidora de drogas por vía intravenosa murió por la

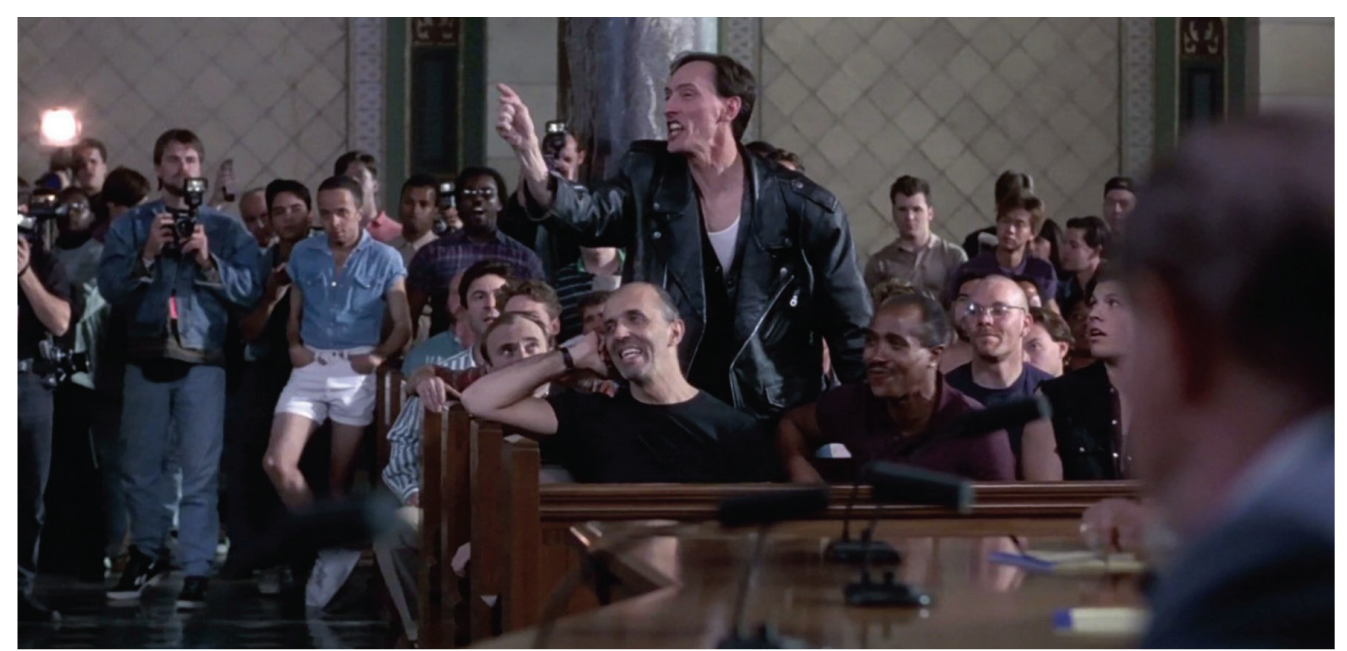

Foto 2. Enojo de los asistentes frente a la posibilidad de cerrar las saunas en San Francisco. 
enfermedad. Por primera vez, las variables de la homosexualidad y del género masculino no están implicadas en un caso de estudio, y Francis hipotetiza sobre el virus: "está en el suministro de sangre". El siguiente caso es de un paciente con hemofilia en Denver, Colorado, que recibió transfusiones.

La investigación da entonces un giro y deja de estar concentrada en la comunidad gay y la transmisión sexual, para considerar la transmisión sanguínea. En una nueva reunión del equipo de investigación, el jefe indica la necesidad de probar que la sangre estuviera contaminada. Nuevamente, se trata de pasar de la hipótesis o de la opinión hacia una evidencia científica. El problema es que para analizar la sangre necesitan saber qué tipo de virus buscar, y eso es una incógnita todavía... Francis propone entonces hacer una prueba de coincidencias tal como hicieron con la investigación de la hepatitis $B$ porque ambas enfermedades coinciden en sus indicadores en un $88 \%$, pero encuentra un fuerte rechazo por parte de su jefe: " $¿$ Ustedes creen que la industria de la sangre va a gastar millones en una idea que es científicamente radical?". Uno de los investigadores sugiere: "si podemos encontrar un paciente que se contagió después de recibir una transfusión, entonces deberíamos mirar su lista de donantes y ver si uno de ellos tiene la enfermedad. Si podemos hacerlo, habremos hecho una conexión. Luego tenemos que probar que ese paciente no pudo contagiarse de otra manera".

Sin embargo, este nuevo camino de la investigación no resulta tan fácil. Cuando piden los datos de los donantes al Banco de Sangre de Nueva York para indagar sobre un paciente que se ha contagiado la enfermedad, se encuentran con la negativa debido al acuerdo de confidencialidad. Su representante dice que no harán nada "a menos de que haya evidencia científica irrefutable de que tal enfermedad existe, y que puede transmitirse por la sangre, y que se compruebe que puede transmitirse mediante las transfusiones"... pero justamente se requieren estos datos previos para hacer esa evidencia científica.

La investigación continúa entonces con el caso de un bebé de 20 meses en el servicio de Pediatría del Centro médico de la Universidad de California, quien tiene la enfermedad y ha recibido 20 transfusiones en los últimos seis meses por presentar la enfermedad hemolítica del recién nacido por grupos Rh. Sus 13 donantes son del Hospital Irwin Memorial. La médica le advierte que no le darán la lista de donantes, aun cuando esté confirmado que es el primer caso irrefutable de transmisión por transfusiones.

Surge entonces la idea de volver a contactar a Selma Dritz, quien le facilita la información de un caso con un donante de sangre que murió dos meses atrás. Sin embargo, este caso tiene una dificultad extra, ya que la causa de muerte fue ocultada por el médico de la familia, y solo puede aclararse cuando dan con el dato de su médico verdadero, quien lo trataba en confidencialidad para que pudiese ocultar su homosexualidad a la familia. Con el dato brindado por el médico se puede unir la enfermedad con la transfusión de sangre.

Enero 1983. 951 casos en Estados Unidos 640 muertes. Se realiza la reunión de todos los investigadores del CDC con los representantes de la industria de la sangre y derivados (Foto 3 ). Se produce aquí un nuevo enfrentamiento entre el jefe del equipo y Francis, ya que el primero intenta ser precavido diciendo que la reunión tiene como objetivo brindarles la información necesaria para que tomen una decisión, y el segundo se inclina por dar abiertamente su opinión.

El jefe del CDC señala: "una opción es la de establecer pautas para evitar que las personas de alto riesgo donen sangre". La discusión se torna emocional: "Prohibir que los homosexuales donen no protegerá el suministro de sangre. Eso los estigmatizará. Me recuerda a los bancos de sangre rechazando las donaciones de negros 


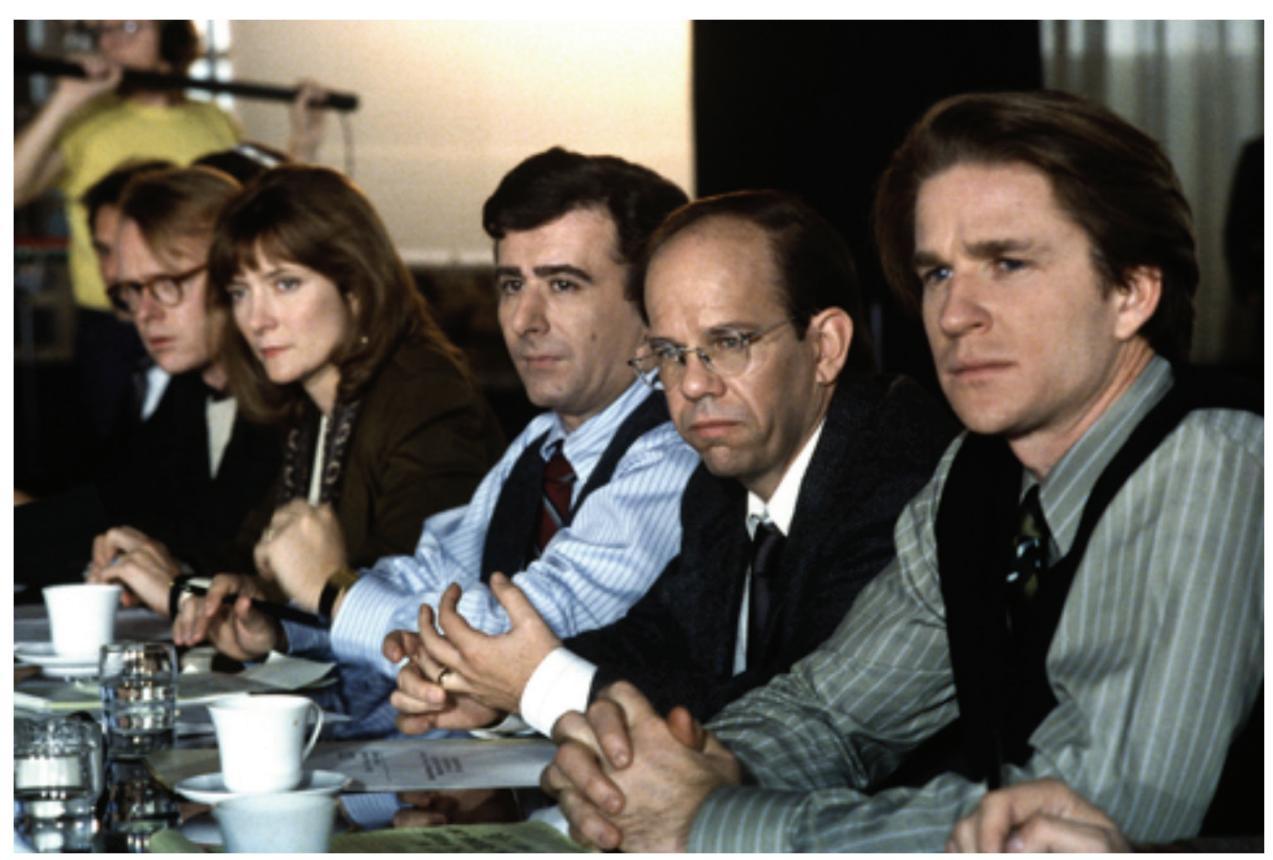

Foto 3. El equipo del CDC en la reunión para tratar las transfusiones con la industria de la sangre.

por temor a la sifilis" y se produce un enfrentamiento con personas que tienen hemofilia -ya que esta enfermedad se ha convertido en su segunda causa de muerte. Los bancos de sangre se niegan a autorizar los análisis de la sangre que poseen hasta que no haya sido probada la enfermedad y su transmisión mediante transfusiones. Francis se enerva e interviene: “¿Cuántos hemofilicos muertos necesitan? ¿Cuánta gente tiene que morir para que hagan algo al respecto? ¿Cien? ¿Mil? iDenos una cifra para que no los molestemos de nuevo, hasta que el dinero gastado en juicios sea más provechoso para salvar gente en lugar de matarla!".

Por otra parte, en esta reunión se propone dar un nombre a la enfermedad, ya que antes se llamaba informalmente Gay-related immune deficiency: surge entonces el nombre Síndrome de Inmunodeficiencia Adquirida (SIDA), para evitar que la enfermedad quede ligada con la homosexualidad. La difusión del nombre del SIDA y la posibilidad de que el contagio sea por vía sanguínea se produce rápidamente gracias a los medios de comunicación. Sin embargo, el equipo no tiene presupuesto para trabajar y el jefe del equipo considera que la intervención de Francis con la industria de la sangre dañó la credibilidad del CDC.

En San Francisco, Selma Dritz facilita al equipo de investigación los datos de una mujer de la alta sociedad que puede ayudarlos en hacer público su contagio de SIDA luego de una cirugía en la que necesitó transfusión de sangre, y así poder ejercer presión sobre el hospital. Sin embargo, los demás bancos de sangre son reticentes a hacerlos, aun cuando los casos de contagios por transfusiones se hayan cuadriplicado en los últimos ocho meses y el $89 \%$ de los pacientes hemofílicos que recibieron una transfusión se ha infectado. 


\section{EN EL FILO DE LA DUDA: INVESTIGACIÓN EPIDEMIOLÓGICA Y ASPECTOS \\ BIOÉTICOS Y PSICOLÓGICOS EN LA PANDEMIA DE VIH \\ IRENE CAMBRA-BADII; MAGÍ FARRÉ; JORGE PÉREZ}

Los siguientes pasos en la investigación se centran en los estudios de laboratorio para la delimitación del nuevo virus. Como Francis no tiene los medios económicos para hacerlo en el laboratorio del CDC, envía muestras biológicas de sus pacientes a sus colegas del Instituto Pasteur en Francia, quienes pueden probar la existencia de un nuevo retrovirus. Esto provoca la ira del científico norteamericano, Dr. Gallo, cuyos resultados no eran positivos, pero seguía teniendo una gran ambición. Más adelante Gallo solicita muestras del virus a los franceses, se apodera del mérito del descubrimiento del virus y trabaja para demostrar su existencia en la sangre que patenta para los Institutos de Salud Nacionales (NIH).

Enero 1983. 2640 casos en Estados Unidos 1092 muertes. Mientras la prensa difunde el alto crecimiento de casos de SIDA en la población norteamericana, se produce una fuerte discusión entre Gallo y Francis sobre la investigación. Francis le increpa sobre los verdaderos objetivos de la investigación: ¿son de rédito personal o social? (Foto 4).

La tensión entre el CDC, Gallo y Montagnier por el descubrimiento se resuelve con un viaje a Paris en abril de 1984. Gallo acuerda con los franceses en publicar tres manuscritos sobre el tema en una prestigiosa revista científica, Science: el CDC hará la parte serológica, Gallo escribirá sobre el análisis de los ácidos nucleicos, y los franceses de las proteínas. El acuerdo de compartir los méritos parece posicionar a Gallo en mejor lugar que los franceses, ya que él no tenía avances en su investigación.

En el CDC, Francis y el jefe se indignan cuando ven a Gallo llevarse todo el crédito de la investigación en la televisión. Francis señala entonces: "La fase uno ya está lista. Tenemos el virus, trabajamos en un análisis sanguíneo. Esta

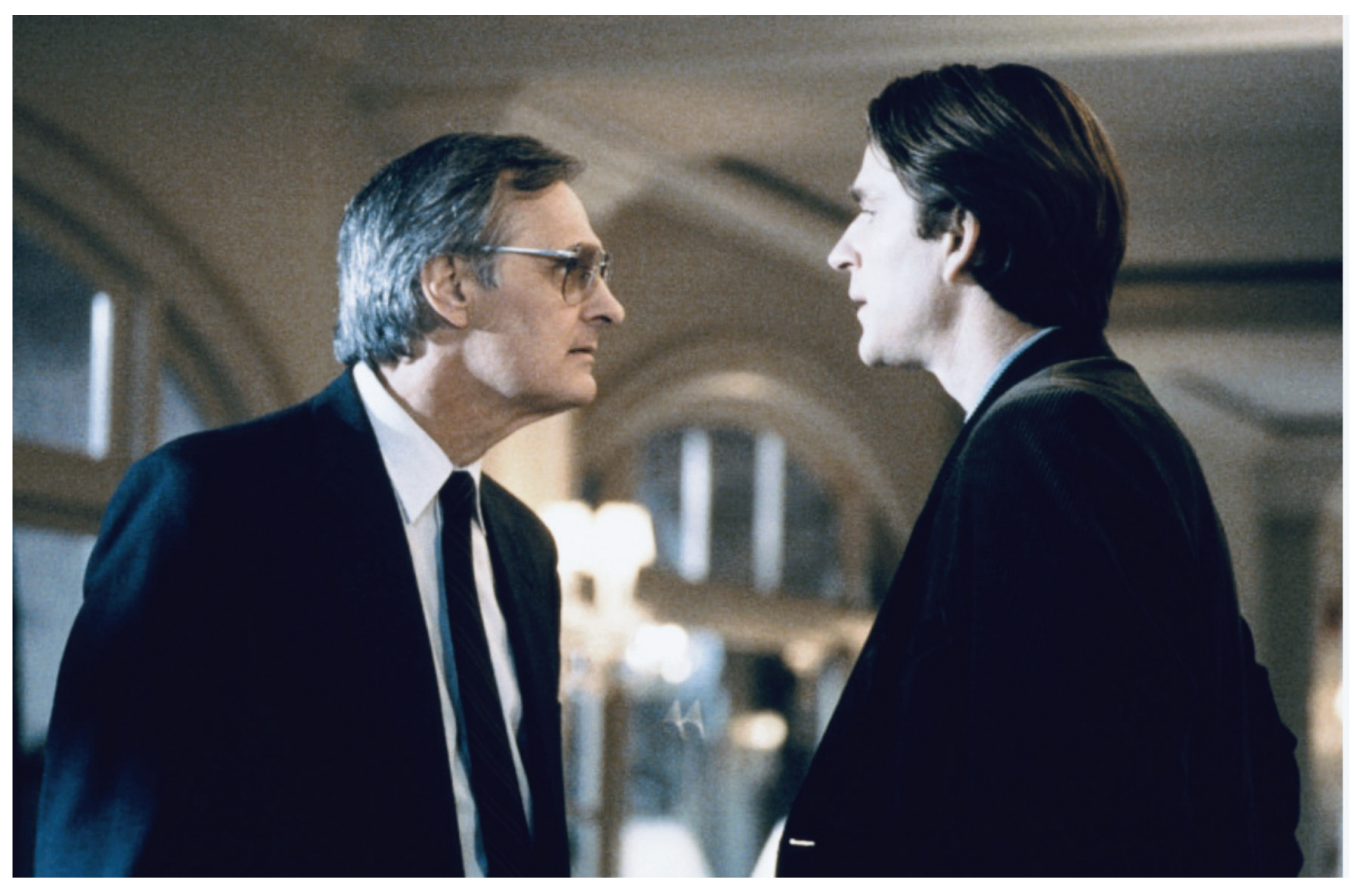

Foto 4. La disputa entre Gallo y Francis. 
es mi propuesta para la fase dos: prevención, educación y cura. Si mi proyecto se aprueba, quiero ser transferido a San Francisco y trabajar desde alli'. El jefe mira el proyecto y su elevado presupuesto y le dice que es irreal. Francis contraataca: "Es barato. Son 15 centavos por persona para hacer a toda la población más segura (...) Espera unos años, y hablaremos de billones de atención médica". El jefe lo mira desanimado, y le dice que, si pide tanto, no obtendrá nada. Amplio conocedor de la escena política -la película incluye en ese momento imágenes documentales de la reelección de Reagan-, el jefe termina teniendo razón, pero Francis se va a San Francisco de todas maneras. Cuando lo despiden en la reunión de equipo, se ve el resumen en su pizarra: 8542 casos, 3921 muertes, 47 estados.

Febrero 1985. 8408 casos en Estados Unidos - 6305 muertes. La discusión entre Gallo y los franceses continúa cuando éstos se enteran de que Gallo obtuvo la patente para el análisis de sangre y hacen una conferencia de prensa en Nueva York indicando que ambos equipos trabajaron con el mismo virus del mismo paciente. La deshonestidad científica de Gallo se explicita nuevamente en las leyendas explicativas al final del film.

Noviembre 1985. La película termina con el retrato de la enfermedad del congresista de las primeras escenas, Bill Kraus. Francis le acompaña y lo sostiene en el final de su vida: "Solía tener miedo a morir. Ahora no. Temo más por lo que le pasa... a la gente que vive". El final de la película incluye luego cientos de imágenes de artistas, deportistas y famosos del mundo entero que han tenido el virus y han fallecido de esta enfermedad, una de las peores pandemias del siglo XX.

\section{ASPECTOS BIOÉTICOS DE LA INVESTIGACIÓN}

En el filo de la duda nos muestra el progreso en el descubrimiento de una nueva enfermedad y su agente etiológico. Es mediante un proceso de investigación clínica, epidemiológica y de laboratorio-básica que se llega a definir la nueva enfermedad del SIDA. La película incluye referencias a los diseños de estudios epidemiológicos y estudios de casos y controles, y los problemas bioéticos que se suscitan en las distintas etapas de las investigaciones.

En los años iniciales del SIDA no era habitual en absoluto preguntar a los pacientes sobre sus preferencias o su conducta sexuales o hábitos de vida, por ello las personas se sorprenden de estas preguntas y sobre todo muestran temor a que su condición sexual sea divulgada o conocida por otros, ya que piensan que puede perjudicarles. Hay que recordar que los familiares de uno de los fallecidos no conocen detalles de su vida íntima, y que éste guarda con mucho celo. La revisión de su agenda muestra varias entradas con un contacto denominado "repairman" ("reparador"), y al llamar a su teléfono se descubre que es uno de los médicos al cuidado de los pacientes con SIDA. Aún en la actualidad éste es un tema controvertido y vale la pena recordar que para la aceptación pública de la propia sexualidad se usa el término "salir del armario".

Es relevante citar que en una escena se requiere que el posible paciente-contacto firme dos consentimientos informados para poder participar en el estudio: uno para realizar una encuesta y el otro para una extracción de sangre. Un ejemplo muy claro de su necesidad para cualquier tipo de investigación clínica.

Otro aspecto que aparece de forma continuada es la necesidad de confidencialidad y de protección de los datos personales. En una de las escenas se facilita una entrevista personal y se entrega la historia clínica de un paciente sin explicarle absolutamente nada de la investigación al mismo, ni pedir su permiso. Un paciente se encuentra de golpe frente a su médico y al investigador en el curso de una visita programada. También se da el hecho de hablar con pacientes que no conocen su enfermedad o que reiteran su voluntad de no conocerla. Aquí la 
actitud secretista de los médicos va claramente contra la autonomía de los pacientes. También existe el derecho a no querer saber, que puede ser contrario al derecho de los contactos a saber que pueden ser contagiados. La necesidad de limitar la autonomía de los pacientes en caso de situaciones excepcionales de salud pública como en las pandemias es un tema para considerar en la visión y análisis de la película, tal como se ve en la discusión por el cierre de las saunas en San Francisco.

Es relevante la defensa de la confidencialidad y el secreto profesional por parte de los representantes de colectivos gay y/o de los bancos de sangre para proteger la identidad de los pacientes, frente a la necesidad de los hemofílicos de conocer este dato para saber si se han contagiado de donantes con SIDA. También se observa en uno de los casos de contagio por transfusiones el hecho de que el médico responsable, en una actitud equivocadamente paternalista, reconoce que no ha explicado la posibilidad de contagio por transfusión a su paciente operada, y la sorpresa mayúscula de la paciente y su esposo al conocerlo por palabras del investigador, que acude a su casa para entrevistarla para conocer detalles de su enfermedad dentro de la investigación epidemiológica.

La película también detalla las dificultades en conseguir financiación para hacer investigación. Se observa en varias escenas la escasez inicial de fondos, que se achaca a la planificada ocultación del mundo gay y por ello de cualquier mención pública de los políticos. El jefe de los investigadores explica que deberán hacer la investigación con fondos propios, y uno de ellos realiza varios viajes para visitar casos-contactos pagándose los gastos de transporte y alojamiento. Una vez conocida la posible relación con las transfusiones, se niega una beca de 750.000 dólares para profundizar en su relación. También aparece la figura de un paciente que aporta fondos particulares para ayudar a la investigación, tal como desde hace años hacen muchas fundaciones, particulares que actúan como mecenas o en la actualidad cualquier ciudadano o institución en el llamado micromecenazgo o crowfunding.

Aparece insistentemente la resistencia de autoridades o empresas, por ejemplo, los bancos de sangre, para facilitar datos que les podrían perjudicar económicamente, poniendo el dinero por encima de la salud y protección de la salud de los ciudadanos. Se muestra de forma clara la actitud corporativista de colectivos o empresas.

Asimismo, el interés de Gallo en la epidemia es un hecho trascendente en el desarrollo de la investigación. Al asociarse con un laboratorio prestigioso, dirigido por un firme candidato previo al premio Nobel de Medicina, da un vuelco a la investigación con la posibilidad de encontrar el agente infeccioso en un laboratorio que tiene los medios necesarios para su búsqueda. El prestigio internacional de Gallo y su influencia se muestran cuando se jacta del hecho de conocer personalmente al editor de la revista Science e insinúa que esta relación le facilita la posibilidad para publicar en esta revista. Sería un ejemplo del llamado "efecto Mateo en ciencia": "quien más tiene, más recibe".

Finalmente hay un aspecto de mala conducta científica, hecho que llevó a investigaciones internas e incluso a juicios. Por un lado, el plagio como apropiación de los datos de otros queda claro cuando Gallo utiliza las muestras de Montagnier para describir el virus con otra denominación (HTLV-III) cuando ya lo había descrito el francés previamente (LAV). La investigación independiente de las muestras de Gallo llega a la conclusión de que eran las mismas muestras que le proporcionó Montagnier y que su identidad genética era superior al $97 \%$. Por otro lado, la ocultación de información para conseguir ventajas y publicar resultados preliminares que después no pueden verificarse o replicarse. 
La petición de patentes y el posible enriquecimiento personal se muestran someramente, pero queda claro que se patentan técnicas descubiertas por terceros sin tener en cuenta su contribución. Al final Gallo y los principales miembros de su laboratorio pudieron seguir con su carrera científica sin ninguna sanción por su mala conducta científica.

\section{ASPECTOS PSICOLÓGICOS SUSCEPTIBLES DE SER TRATADOS DESPUÉS DE LA PELÍCULA}

La película está llena de relaciones humanas $y$, por tanto, podría servir para reflexionar sobre procesos básicos, sobre diferencias individuales y, especialmente, sobre psicología social, sobre el comportamiento humano dentro de una comunidad.

En referencia a los procesos básicos en Psicología, en la película aparecen secuencias relacionadas con tres de los más importantes sentimientos humanos: el miedo, la ira y la felicidad. El miedo está presente en diversas escenas, una de las cuales es la reacción del matrimonio pudiente donde la mujer había sido contagiada en una transfusión. Una clara referencia a la ira aparece cuando el Dr. Gallo se entera que el Dr. Francis ha suministrado información al grupo científico francés. También la felicidad es mostrada de forma reiterativa en diversos miembros del equipo científico protagonista ante los nuevos avances en el conocimiento de la enfermedad. Un proceso básico importante es el pensamiento asociado a la resolución de problemas y en el film se muestra de forma muy explícita todo el proceso ante una dificultad de salud muy grave. Ello daría lugar a reflexionar sobre los pasos para llegar a una solución eficiente y a considerar las variables relacionas con la experiencia que podrían dificultar la resolución del caso, como podría ser la tendencia a confirmar hipótesis, tal como se ve en la escena de "serendipity" de Francis ante el juego del Pac-Man.
Ejemplos de diferencias individuales, de personalidad, también quedan patentes en la película al mostrar comportamientos diferentes ante el riesgo para contraer la enfermedad como manifestarían los defensores de mantener abiertas las saunas o, en las antípodas, el líder político del movimiento gay.

Asimismo, la película sería especialmente útil para ilustrar muchos fenómenos de Psicología social. En ella aparecen de forma patente los diferentes roles sociales (jefe vs subordinado), el fenómeno del conformismo social, el hecho de adaptarse a los planteamientos de la mayoría en la asamblea gay, o el tema de la obediencia: hacer algo, aunque no estés de acuerdo ante la decisión de una persona con rol superior (como hace el jefe del equipo del CDC ante los políticos o el gobierno).

La película puede dar pie para reflexionar sobre las actitudes sociales, desde aspectos políticos e históricos de Estados Unidos, hasta profundizar en los prejuicios ante ciertos colectivos de personas: recordemos que durante mucho tiempo la enfermedad fue considerada como un problema gay.

También se ilustra el tema de la agresión ya que aparecen comportamientos agresivos que, aunque no sean físicos, sí son verbales y que pueden causar daño a la persona agredida (como hace Gallo, indignado, frente a Francis). Si bien el ser humano está preparado biológicamente para ser agresivo, también lo está para ser altruista. En el film encontramos diversas muestras de comportamiento altruista, de ayuda al prójimo (como por ejemplo el equipo médico en África arriesgando un posible contagio, o el coreógrafo aportando fondos para la investigación).

En la película aparecen numerosas relaciones interpersonales que ilustran el tema de la atracción interpersonal, como relaciones de rivalidad (Gallo vs Montagnier), de amistad (buena relación entre los miembros del equipo protagonista) o de relaciones amorosas (líder del movimiento 
gay y su pareja). Asimismo, resulta ideal para comentar el tema de la orientación sexual y de los prejuicios.

El film permite también discutir sobre algunos aspectos de Psicología de la Salud como el estrés (trabajo agotador de miembros del equipo) o el enfrentamiento con la enfermedad (a través de la historia del líder político del movimiento gay, del coreógrafo y del azafato).

Finalmente, además de lo comentado, la película podría tener alguna referencia psicoanalítica al considerar los recueros y sueños de Francis sobre los muertos que incineran en el Zaire y los vivos que le reclaman vivir (le toman del brazo, le reclaman entender). Dicho trauma queda reparado en una de las escenas finales donde se despide ante el lecho de muerte del dirigente político del movimiento gay.

\section{CONCLUSIONES}

En el filo de la duda fue estrenada en 1993 y su final narrativo se ubica en 1985 . El panorama sobre la pandemia de VIH ha cambiado bastante en los años siguientes, principalmente con la publicación de la secuencia de sus genomas y la caracterización de sus proteínas, y el surgimiento de los primeros tratamientos antirretrovirales en 1987. Desde 1994, la ONU coordina un programa internacional llamado ONUSIDA, dedicado a la actuación científica y social para la prevención y tratamiento de enfermedades relacionadas con el VIH. En su página web, se señala que en 2019 se contagiaron de VIH 1.7 millones de personas, $y$ que en la actualidad hay 38 millones de personas conviviendo con el virus. Asimismo, las mujeres y las niñas representan aproximadamente el $48 \%$ de nuevas infecciones por el VIH en 2019, y en África subsahariana, el $59 \%$.

Esta película permite seguir perfectamente una investigación epidemiológica modelo para la detección de nuevas enfermedades. La narración incluye las entrevistas iniciales a médicos, pacientes y familiares, buscando aspectos coincidentes que permitan analizar una correlación o causalidad de la enfermedad, el aporte de informantes clave, la necesidad de ir comprobando hipótesis paulatinas y no quedarse solamente con la intuición inicial, la incorporación de datos de la realidad circundante (que, por ejemplo, ampliaron el grupo de afectados dejando de centrarse en la comunidad gay, permitiendo abrir una nueva hipótesis sobre la transmisión sanguínea), la importancia de la delimitación del agente patógeno en el laboratorio, y la necesidad de hacer programas de educación y prevención para impedir que el virus se siga propagando.

Asimismo, nos conecta con el apremio investigativo de tener que encontrar una rápida respuesta frente a una crisis sanitaria y social. En este sentido, es importante que la película mencione la cantidad de contagios y muertes, y su multiplicación en todo el país, a medida que avanza la trama. Este apremio aparece como justificativo para las "excepciones" bioéticas que se tratan en el film, principalmente respecto de la confidencialidad y la privacidad, y los límites frente a la autonomía personal.

En el filo de la duda permite vislumbrar a la pandemia no solo en su dimensión médica sino también social y política, siguiendo los juegos de alianzas y enemistades de los equipos de investigación, las comunidades gay y de pacientes, el rol del CDC y la importancia de la política en todas las situaciones. La enfermedad aparece retratada desde una perspectiva biopsicosocial, lo cual aporta distintas claves para pensar su transmisión y evolución.

La discriminación sufrida por la comunidad gay con los nombres "neumonía gay", "cáncer gay" e incluso "la enfermedad rosa" nos habla de cómo la sociedad tiende a evitar asimilar la pandemia en un primer momento, aislándola en un grupo, y cómo esto incide tanto en la percepción del riesgo como en la voluntad política de apoyar estas investigaciones. 
Asimismo, la película no ahorra críticas para las industrias ligadas con la salud -como la de las transfusiones de sangre- y para los científicos más preocupados por su fama personal que por el beneficio de la humanidad.

Estos múltiples puntos de vista para analizar la película -respecto del proceso investigativo, tanto epidemiológico como de laboratorio, las cuestiones bioéticas implicadas, el análisis de los factores psicológicos y de las tramas sociales y políticas-pueden dar lugar a distintos objetivos educativos en caso de utilizarse esta película en la enseñanza de las ciencias de la salud, como ya se ha hecho con otras películas sobre el VIH ${ }^{6,10-12}$.

La perspectiva de los investigadores aparece retratada de manera excelente en el film. Se puede ver el entusiasmo por generar conocimiento, el valor del insight del pensamiento y de las casualidades que brindan las claves para el desarrollo de una investigación. Asimismo, se puede presenciar el sacrificio de la vida personal de cada uno de ellos, que trabajan horas extras, sin presupuesto, con espacio limitado y un equipo de laboratorio obsoleto en el CDC, y el impacto que les produce el hablar con las personas afectadas por la enfermedad.

La perspectiva de los pacientes o afectados no está tan presente en el film, como ha sido criticado anteriormente ${ }^{13}$. Surgen algunas impresiones a través del relato de Bill Kraus, de las reuniones de la comunidad gay, con sus luchas y tensiones, y del paciente asintomático encarnado por Richard Gere, que financia personalmente la investigación cuando se entera de su enfermedad. También fue criticada la presentación del azafato como el paciente cero, tanto en la película como en el libro, ya que refuerza la idea de la culpabilidad de una sola persona, y además extranjera, que supuestamente había ingresado el virus en los Estados Unidos en los años $1980^{4,13,14}$.
Para acercarse a la visión de los pacientes en la pandemia de $\mathrm{VIH}$, recomendamos la relativamente reciente 120 pulsaciones por minuto / 120 battements par minute (2017) de Robin Campillo, The normal heart (2014) de Ryan Murphy, El club de los desahuciados / Dallas Buyers Club (2013) de Jean-Marc Vallée, y la historia de Ed Harris en Las horas / The hours (2002) de Stephen Daldry, más allá de la clásica Philadelphia (1993) de Jonathan Demme.

Una última reflexión respecto del título de la película. A partir del inglés original, And the band played on, se tradujo literalmente en Latinoamérica como Y la banda siguió tocando, cuyo significado está asociado a la crítica respecto de que los negocios y las rutinas sigan marchando sin detenerse, aun en medio de una epidemia como la orquesta tocando en el hundimiento del Titanic. La traducción española, En el filo de la duda, parece más cercana a la premura y la lógica del proceso de investigación que se representa en el film.

La actual pandemia por coronavirus SARSCoV-2 permite comparar el proceso investigador entre la actual COVID-19 y el pasado del VIH-SIDA. Las bases de las investigaciones epidemiológicas aún son de uso actual, con la búsqueda de los casos índice o los contactos. En esta ocasión, la identificación del virus ha sido muy rápida, con competencia internacional y un gran papel de la industria para conseguir un tratamiento nuevo o una reposición terapéutica de medicamentos conocidos, así como el rápido desarrollo de una vacuna, pero de nuevo hay una carrera entre científicos para ser los primeros por publicar a toda costa, a veces con una calidad cuestionable y con nuevas dudas bioéticas ${ }^{15}$.

No podemos finalizar sin manifestar que la película resulta una buena herramienta para fomentar el aprendizaje sobre investigación científica, sobre psicología y sobre bioética, y que mantiene intacta su actualidad luego de casi treinta años de su estreno. 


\section{EN EL FILO DE LA DUDA: INVESTIGACIÓN EPIDEMIOLÓGICA Y ASPECTOS \\ BIOÉTICOS Y PSICOLÓGICOS EN LA PANDEMIA DE VIH \\ IRENE CAMBRA-BADII; MAGÍ FARRÉ; JORGE PÉREZ}

\section{NOTA FINAL}

Nos gustaría comentar el origen del presente escrito: los autores, que tenemos lazos de amistad, hemos colaborado en diversos proyectos científicos y, especialmente, de innovación docente. Coincidimos en nuestra pasión por el cine y por la docencia y, por tanto, hemos colaborado en diversas ocasiones con la RMC con la que nos sentimos ligados sentimentalmente. Aprovechando el confinamiento del COVID-19 en 2020, y dada nuestra afición al cine, decidimos crear un juego en el que cada día uno de los autores presenta un fotograma de una película que los otros dos han de adivinar. Para esto creamos un grupo de WhatsApp al que denominamos "Cinéfilos confinados" que continuamos manteniendo actualmente. Al recibir los tres la invitación de Agustín Hidalgo, coordinador del número especial de la RMC, decidimos realizar un artículo conjunto y creímos que la película seleccionada serviría perfectamente para cumplir con nuestro objetivo.

\section{REFERENCIAS}

1. Shilts A. And the Band Played On. New York: St. Martin's Press, 1987.

2. García Sánchez JE, Fresnadillo MJ, García Sánchez E. El cine en la docencia de las enfermedades infecciosas y la microbiología clínica. Enfermedades Infecciosas y Microbiología Clínica. 2002; 20(8), 403-6.

3. Ameijeiras-Marra S, Morón-Marchena JA. Educación para la salud a través del cine. Comunicar. 1998; 6(11): 123-8.

4. Pais de Lacerda A. El cine como documento histórico: el SIDA en 25 años de cine. Rev Med Cine. 2006; 2(3): 102-13.
5. Alarcón WA, Aguirre CM. El cine en la docencia de la medicina: cuidados paliativos y bioética. Rev Med Cine. 2007; 3(1): 32-41.

6. Merino Vasiloff LA, Esquivel Torres GP, Lifschitz Pagliera V. El cine como herramienta en la enseñanza de la Microbiología. Rev Med Cine. 2008; 4(4): 145-7.

7. Pérez J, Aramburu J, Baños JE, Bosch F, Díez J, Farré M, Girvent M, Sentí M, Valverde O. Uso del cine comercial como herramienta docente en estudios en ciencias de la salud. Una experiencia multidisciplinar y colectiva. FEM. 2014; 17(3):131-5.

8. Cambra Badii I, Baños JE. The University goes to the movies: our experience using feature films and tv series in teaching health sciences students. En: Kim S, editor. Medical Schools: Past, Present and Future Perspectives. New York: Nova Publishers. p. 105-148.

9. https://www.unaids.org/es [Fecha de consulta: 1 de setiembre 2020]

10. Farré M, Arribas S, Pérez J, Baños J. El uso de películas comerciales para comprender los principios bioéticos en la investigación clínica. Rev Med Cine. 2013; 9(4):151-5.

11. Farré M, Bosch F, Roset PN, Baños JE. Putting clinical pharmacology in context: the use of popular movies. J Clin Pharmacol. 2004; 44:30-6.

12. De Haan Bosch M, Gómez-Tomás A, Baños JE, Farré M. Dallas Buyers Club (2013): la investigación clínica con fármacos durante la epidemia del sida de los años 80. Rev Med Cine. 2015; 11(2): 73-81.

13. McKay RA. "Patient Zero": the absence of a patient's view of the early North American AIDS epidemic. Bull Hist Med. 2014;88(1):161-94.

14. Darrow, W.W. And the Band Played on: Before and After. AIDS Behav. 2017; 21:2799-2806.

15. Fritz Z, Huxtable R, Ives J, Paton A, Slowther AM, Wilkinson D. Ethical road map through the covid-19 pandemic. BMJ. 2020 May 21;369:m2033. 


\begin{tabular}{|c|c|}
\hline & $\begin{array}{l}\text { Irene Cambra Badii. Licenciada y Doctora en Psicología. Durante más de } \\
\text { diez años, fue investigadora y profesora en la Universidad de Buenos Aires } \\
\text { (Argentina). Completó su formación postdoctoral en la Universitat Pompeu } \\
\text { Fabra (Barcelona) donde es miembro del Grupo de Investigación en Edu- } \\
\text { cación en Ciencias de la Salud (GRECS) en el Departamento de Ciencias } \\
\text { Experimentales y de la Salud. Desde } 2019 \text { es investigadora en la cátedra de } \\
\text { Bioética de la Universitat de Vic-Universitat Central de Catalunya. }\end{array}$ \\
\hline & $\begin{array}{l}\text { Magi Farre. Albaladejo es médico especialista en Farmacología Clínica. } \\
\text { Catedrático de Farmacología en la Universitat Autònoma de Barcelona y } \\
\text { Jefe del Servicio de Farmacología Clínica del Hospital Universitario Ger- } \\
\text { mans Trias i Pujol en Badalona (Barcelona). Anteriormente fue Consultor } \\
\text { en el Instituto Hospital del Mar de Investigaciones Médicas-IMIM. Sus áreas } \\
\text { de trabajo son la neuropsicofarmacología clínica, las drogas de abuso y las } \\
\text { propiedades de los antioxidantes naturales. En el ámbito académico tiene } \\
\text { interés en los métodos de innovación docente en Farmacología y Bioética. }\end{array}$ \\
\hline & $\begin{array}{l}\text { Jorge Pérez Sánchez. Es profesor titular jubilado de Psicología Médica y } \\
\text { miembro del Grupo de Investigación Educativa en Ciencias de la Salud } \\
\text { (GRECS) de la Universidad Pompeu Fabra (UPF). Fue Director de la Oficina } \\
\text { Educativa (1998-2016) y Decano (1999-2011) de la Facultad de Ciencias de } \\
\text { la Salud y de la Vida de la UPF. Recibió el premio a la trayectoria docente } \\
\text { del Consejo Social de la UPF en } 2006 \text { y la distinción Vicens Vives de la } \\
\text { Generalitat de Catalunya a la calidad docente en } 2011 .\end{array}$ \\
\hline
\end{tabular}

